DOI: $10.5216 /$ cab.v12i1.9612

\title{
UTILIZAÇÃO DE Spirulina platensis COMO SUPLEMENTO ALIMENTAR DURANTE A REVERSÃO SEXUAL DA TILÁPIA-DO-NILO (VAR. CHITRALADA) EM ÁGUA SALINA
}

\author{
Ricardo Lafaiete Moreira, ${ }^{1}$ Rafael Rômulo de Oliveira Martins ${ }^{2}$ E \\ WLADIMIR Ronald LoBo FARIAS ${ }^{3}$
}

\author{
1. Doutorando na Universidade Federal do Ceará (UFCE). E-mail: Ricardolafaiete@hotmail.com \\ 2. Engenheiro de Pesca formado pelo Departamento de Engenharia de Pesca da Universidade Federal do Ceará \\ 3. Professor adjunto III da Universidade Federal do Ceará.
}

RESUMO

\begin{abstract}
Neste trabalho objetivou-se avaliar a influência de Spirulina platensis como suplemento alimentar em pós-larvas de tilápia-do-nilo cultivadas em água salina. $\mathrm{O}$ delineamento constou de dois tratamentos com três repetições cada. No primeiro os animais foram alimentados com ração contendo o andrógeno 17 a-metiltestosterona e $S$. platensis e, no segundo, apenas ração com o hormônio. Ao final da reversão (28 dias), as tilápias que receberam S. platensis apresentaram pesos médios de $1,17 \pm 0,16 \mathrm{~g}$, resultados superiores significantemente aos dos animais alimentados apenas com ração, os quais alcançaram peso médio de $0,62 \pm 0,38 \mathrm{~g}(\mathrm{P}<$ $0,05)$. No entanto, as taxas de sobrevivência não tiveram diferença
\end{abstract}

significativa $(\mathrm{P}<0,05)$. Ao final do cultivo (78 dias), a análise gonadal dos peixes evidenciou índices de $47,5 \%$ de machos para os peixes cultivados sem a microalga e $59,09 \%$ para os peixes cultivados com S. platensis. Com a realização deste trabalho, foi possível concluir que a tilápia-do-nilo apresentou bom desenvolvimento e taxas de sobrevivência mais satisfatórias durante a fase de reversão sexual na presença de $S$. platensis, em relação àquelas alimentadas apenas com ração, em água salina. No entanto, não foi possível obter índices aceitáveis de reversão sexual após a administração, por meio da ração, do hormônio masculinizante através da ração.

PALAVRAS-CHAVES: Microalga, Oreochromis, reversão sexual, salinidade, $17 \alpha$ - metiltestosterona.

\section{ABSTRACT}

\section{USE OF Spirulina platensis AS FOOD SUPPLEMENT DURING NILE TILAPIA (CHITRALADA STRAIN) SEX REVERSAL IN SALT WATER}

This study aimed to evaluate the Spirulina platensis influence as a food supplement in Nile tilapia post-larvae grown in saline water. The experiment consisted of two treatments with three replicates. In first one the animals were fed ration containing the androgen $17 \alpha$-methyltestosterone and S. platensis, and in the other only diet with the hormone. At the end of the reversal (28 days), tilapia that received $S$. platensis showed average weights of $1.17 \pm 0.16 \mathrm{~g}$, significantly superior to the animals fed only ration, which reached an average weight of $0.62 \pm 0.38 \mathrm{~g}(\mathrm{P}<$
$0.05)$; however, survival rates showed no significant difference $(\mathrm{P}<0.05)$. At the end of the experiment (78 days), fish gonadal analysis showed indices of $47.5 \%$ of males for fish reared without microalgae and $59.09 \%$ for fish reared with $S$. platensis. It was conclude that Nile tilapia showed good growth and survival rate in the presence of $S$. platensis, compared to the fish fed only diet in saline water. However, it was not possible to obtain acceptable rates of sex reversal after the administration of masculinizing hormone through the diet.

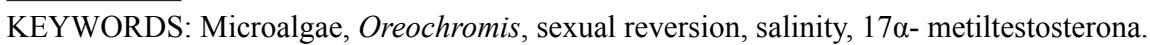




\section{INTRODUÇÃO}

Com taxa de crescimento anual superior a $13 \%$ nas últimas décadas, a tilapicultura é uma das atividades agropecuárias que mais se desenvolvem no mundo. As tilápias são cultivadas em mais de cem países de regiões tropicais e subtropicais, sendo a tilápia-do-nilo a espécie mais importante do gênero Oreochromis (FAO, 2009). A versatilidade alimentar está dentre algumas de suas principais características zootécnicas (HAYASHI et al., 1999). SANTOS et al. (2007) viabilizaram seu crescimento com uso de alimentos compostos da fauna acompanhante da pesca do camarão, enquanto HISANO et al. (2008) comprovaram que a levedura íntegra pode ser utilizada como alimento funcional na dieta dessa espécie.

Um dos grandes entraves na produção de peixes é o fornecimento impróprio de alimento durante o período pós-larval, estágio em que eles encontram-se mais frágeis e suscetíveis à baixa qualidade de água, ao manejo inadequado e a doenças. Todos esses aspectos devem ser observados, uma vez que a fase de larvicultura é fundamental para o sucesso da etapa final da produção. Durante os primeiros dias de vida, a larva supre suas necessidades energéticas com o vitelo, pois nem a boca encontra-se aberta nem o trato intestinal está formado. Após o consumo das reservas proteicas, sua alimentação passa a ser exógena e é composta principalmente por microalgas e zooplâncton (SIPAUBA-TAVARES; ROCHA, 2003).

No caso da tilápia-do-nilo é necessária a oferta de ração contendo o hormônio masculinizante 17 $\alpha$ - metiltestosterona para a obtenção de indivíduos monosexo (machos), já que essa espécie possui alta prolificidade e maturação sexual precoce (MAINARDES-PINTO et al., 2000). Uma das técnicas que vêm sendo largamente utilizadas para aumentar a sobrevivência e o crescimento na larvicultura de peixes é a adição de dietas naturais contendo ácidos graxos poli-insaturados, os quais são essenciais para o bom desenvolvimento de muitas espécies (BELAY et al., 1996). As pesquisas sobre a nutrição de larvas também estão sendo desenvolvidas, buscando limitar o emprego de alimento vivo aos primeiros dias de vida, substituindo-o por alimentos totalmente artificiais (MEURER et al., 2003).

Uma microalga que possui grande potencial para o enriquecimento de dietas para tilápias é a Spirulina platensis, que tem como principal característica ser fotossintética, planctônica, e formar populações volumosas em corpos tropicais e subtropicais (VONSHAK, 1997). Sua composição química é responsável por seu elevado valor nutricional (MIRANDA et al., 1998), destacando-se também das demais microalgas pelo alto conteúdo proteico, alcançando até $70 \%$ de seu peso seco e possuindo considerável teor de aminoácidos (62\%), segundo PIÑERO-ESTRADA et al., (2001).

Resultados que contradizem a vantagem do alimento natural no ambiente de cultivo foram encontrados por TENDENCIA et al. (2005), os quais pesquisaram os efeitos da Chlorella sp. na diminuição de bactérias na água de cultivo de tilápia e camarão. Os estudos mostraram que o cultivo apenas de tilápia foi mais eficiente no controle do crescimento bacteriano que a coexistência do peixe e da microalga.

A tilápia-do-nilo é um peixe oriundo de ambientes dulciaquícolas; entretanto, estudos mostram que ela pode ser aclimatada em águas com salinidade de 30 g. $\mathrm{L}^{-1}$ ou superior a isso, embora haja mortalidade considerável a partir de 23 g.L $L^{-1}$. Esse fenômeno é atribuído ao estresse hiperosmótico, que torna o animal suscetível a enfermidades (ERNST et al., 1991; KUBITZA, 2000; FONTAINHAS-FERNANDES et al., 2002; EL-SAYED et al., 2005).

A expansão do cultivo da tilápia-do-nilo em água salgada e salobra tem atraído a atenção de empreendedores aquícolas nos últimos anos, pois tilápias cultivadas nesses ambientes apresentam qualidade de carne superior à observada em animais mantidos em água doce. É que a água salgada e salobra minimizam os problemas de off-flavor, ou seja, a presença de sabores e odores indesejáveis, resultando em produtos atrativos quanto ao aspecto sensorial (CYRINO et al., 2004; KUBITZA, 2005).

Devido à importância da espécie em questão e à potencialidade da $S$. platensis, no presente trabalho objetivou-se avaliar a influência desse alimento natural em pós-larvas de tilápia-do-nilo cultivadas em água salina.

\section{MATERIAL E MÉTODOS}

As pós-larvas (pl's) de tilápia-do-nilo foram obtidas na Estação de Piscicultura Raimundo Saraiva da Costa/DEP/CCA/UFC. A água com salinidade de 
35 g.L.-1 foi coletada na Praia de Iracema, Fortaleza, Ceará, e transportada em recipientes de polipropileno para o local da pesquisa.

Para o cultivo de $S$. platensis foi preparado meio de cultura utilizando cloreto de sódio $\left(30\right.$ g.L $\left.\mathrm{L}^{-1}\right)$; bicarbonato de sódio (10 g. $\left.\mathrm{L}^{-1}\right)$; NPK - nitrogênio, fósforo e potássio $\left(1 \mathrm{~g} . \mathrm{L}^{1}\right)$ e superfosfato triplo $\left(0,1 \mathrm{~g} . \mathrm{L}^{-1}\right)$. Inicialmente, os sais foram macerados e diluídos em um recipiente plástico contendo $10 \mathrm{~L}$ de água e, posteriormente, os fertilizantes agrícolas (NPK e superfosfato triplo) foram macerados e adicionados à mistura. Em seguida, a água foi submetida a forte aeração por 24 horas e finalmente decantada. Obteve-se o inóculo inicial transferindo-se $300 \mathrm{~mL}$ do cultivo preestabelecido para um Erlenmeyer de 1 L. Após cinco dias, o inóculo foi transferido para o meio de cultura, iniciando o cultivo em larga escala. A quantidade ofertada aos peixes foi monitorada com o auxílio de um espectrofotômetro e foi mantida constante na água de cultivo, no valor de $20 \%$ de absorbância da luz no comprimento de onda de $680 \mathrm{~nm}$. Realizou-se coleta da microalga S. platensis por meio da filtração da cultura em malha de $60 \mu \mathrm{m}$ acoplada a um recipiente tubular de PVC. A biomassa algal retida na rede foi lavada com água destilada para retirar o excesso de meio de cultivo e transferida para um Becker. Filtraram-se, aproximadamente, $15 \mathrm{~mL}$ do cultivo preestabelecido para cada tratamento em uma única oferta diária.

A ração comercial em pó (50\% $\mathrm{PB})$, nutricionalmente completa, era composta por farelo de glúten, milho, farelo de soja, milho integral moído, cloreto de sódio, premix vitamínico mineral, farinha de peixe e gordura vegetal estabilizada. A composição centesimal da ração, segundo seu fabricante, é $10 \%$ de umidade, $50 \%$ de proteína bruta, $8 \%$ de extrato etéreo, $6 \%$ de matéria fibrosa, $13 \%$ de matéria mineral, $8 \%$ de cálcio e 1,2\% de fósforo. Para a incorporação do hormônio sexual na ração, foi preparada uma solução estoque, dissolvendo-se $6 \mathrm{~g}$ do hormônio $17 \alpha$-metiltestosterona em $1 \mathrm{~L}$ de álcool etílico absoluto (95\%). Para o preparo de $1 \mathrm{~kg}$ da ração, $10 \mathrm{~mL}$ da solução estoque foram diluídos em $500 \mathrm{~mL}$ de álcool comum ou comercial, segundo a metodologia de SHELTON et al. (1981). A oferta diária de ração com hormônio, dividida em seis refeições, foi de $20 \%$ do peso vivo dos animais.

Os parâmetros físico-químicos oxigênio dissolvido (OD), temperatura e $\mathrm{pH}$ da água de cultivo, em ambas as fases, foram determinados duas vezes por semana, utilizando-se oxímetro digital modelo YSI 550A para os dois primeiros, e um medidor de bancada modelo MARCONI PA 200 para o último.

As pl's com peso e comprimento total médios de $0,01 \pm 0,01 \mathrm{~g}$ e $0,8 \pm 0,01 \mathrm{~cm}$, respectivamente, foram distribuídas, aleatoriamente, em seis aquários de $20 \mathrm{~L}(20 \times 10 \times 10 \mathrm{~cm})$. Aclimataram-se os peixes nas próprias unidades experimentais a partir de água doce declorificada, por intermédio de substituição, elevando-se a salinidade em 5 g.L. - $^{-1}$ diariamente até que atingisse o nível desejado de $25 \mathrm{~g} . \mathrm{L}^{-1}$. A salinidade foi regulada e aferida constantemente com o auxílio de refratômetro modelo ATAGO (S/Mill). No início da aclimatação, as pós-larvas já estavam recebendo ração com hormônio.

O experimento consistiu de dois tratamentos com três repetições cada um. Para um dos tratamentos foi oferecida ração comercial e $S$. platensis e, para o outro, apenas ração comercial (controle). Cada repetição teve vinte peixes, totalizando 120 animais no experimento. A duração dessa fase foi de 28 dias, período necessário para a reversão sexual. Realizou-se a biometria (peso e comprimento) no início, após quinze e 28 dias do experimento. Depois desse procedimento os animais foram acondicionados em tanques de crescimento de $3.000 \mathrm{~L}(3 \times 1 \times 1 \mathrm{~m})$, na densidade de 0,03 peixe por litro, durante cinquenta dias. Esse método teve por finalidade aumentar o tamanho dos animais e aperfeiçoar a verificação da eficácia da masculinização. A análise foi realizada por meio da observação microscópica das gônadas de cada indivíduo, utilizando-se a técnica do aceto-carmim descrita por GUERRERO \& SHELTON (1974), adaptada e validada para tilápia-do-nilo por WASSERMANN \& AFONSO (2002).

O ganho de peso médio (GPI) foi calculado a partir da seguinte fórmula: GPI $(\mathrm{g})=\mathrm{Wf} / \mathrm{Nf}$, em que $\mathrm{Wf}=$ peso médio da biomassa de cada tratamento e $\mathrm{Nf}=$ número de indivíduos em cada biometria. Para a determinação do comprimento médio mediam-se todos os peixes com paquímetro de precisão $0,01 \mathrm{~cm}$. Para a sobrevivência ( $\mathrm{S} \%$ ) foi utilizada a seguinte fórmula: $\mathrm{S} \%=100 \times \mathrm{Nf} / \mathrm{Ni}$, no qual, $\mathrm{Nf}=$ número de peixes no final do experimento e $\mathrm{Ni}=$ número de peixes no início do experimento. As médias de peso e comprimento foram submetidas a análise de variância com fator único (ANOVA) e, posteriormente, ao teste 
t independente para médias. Todos os testes foram realizados no nível de 5\% de significância estatística, utilizando-se a função estatística do programa ORIGIN $^{\circledR}$ 6.0 Professional (MICROCAL SOFTWARE, 1999). Utilizou-se transformador angular (arco seno da raiz quadrada) para homogeneizar as variâncias dos valores de sobrevivência, porém esses valores são aqui apresentados na sua forma original.

\section{RESULTADOS E DISCUSSÃO}

Os parâmetros físico-químicos da água de cultivo (temperatura, oxigênio dissolvido e $\mathrm{pH}$ ) não apresentaram variações durante a realização do experimento, conforme sumariza a Tabela 1, e ficaram dentro dos limites estabelecidos para o cultivo de tilápias (KUBITZA, 2000; VINATEA, 2004).

TABELA 1. Valores médios e desvios dos parâmetros físicoquímicos obtidos durante a realização do experimento

\begin{tabular}{lccc}
\hline \multicolumn{3}{c}{ Parâmetros físico-químicos } \\
\hline & $\begin{array}{c}\text { Temperatura } \\
\left({ }^{\circ} \mathrm{C}\right)\end{array}$ & OD $\left(\mathrm{mg} . \mathrm{L}^{-1}\right)$ & $\mathrm{pH}$ \\
$\begin{array}{l}\text { Spirulina platensis } \\
+ \text { ração }\end{array}$ & $27,5 \pm 0,01$ & $4,8 \pm 0,03$ & $8,5 \pm 0,12$ \\
Ração & $27,6 \pm 0,01$ & $5,1 \pm 0,02$ & $8,7 \pm 0,05$ \\
\hline
\end{tabular}

As figuras 1 e 2 apresentam os valores de peso e comprimento médio das pl's de tilápia durante os 28 dias do cultivo. Aos quinze dias, os peixes que receberam apenas ração e ração com $S$. platensis atingiram pesos médios de $0,42 \pm 0,08 \mathrm{~g}$ e $0,19 \pm 0,06 \mathrm{~g}$, respectivamente, observando-se diferença significativa $(\mathrm{P}<0,05)$. O peso médio dos peixes que receberam a microalga foi o dobro dos resultados obtidos para o tratamento com a ausência de $S$. platensis. Ao final da masculinização (28 dias), as tilápias que receberam $S$. platensis tiveram pesos médios finais de $1,17 \pm 0,16$ $\mathrm{g}$, com desempenho superior ao dos animais alimentados apenas com ração, que alcaçaram peso médio de $0,62 \pm 0,38 \mathrm{~g}(\mathrm{P}<0,05)$. Essa significativa diferença com a média de peso dos indivíduos do tratamento com $S$. platensis continuou sendo duas vezes superior à que foi obtida para os peixes do tratamento sem a microalga. Valores do crescimento em comprimento também foram estatisticamente superiores $(\mathrm{P}<0,05)$. Os resultados de desempenho das tilápias alimentadas com a microalga foram maiores que os descritos na literatura (EL-SAYED \& KAWANNA, 2004; YASUI et al., 2007; BEZERRA et al., 2008). Recentemente MOREIRA et al. (2010) avaliaram o efeito da inclusão de microalgas de água doce e $S$. platensis, copépodos e copépodos enriquecidos com $S$. platensis como suplementos alimentares para tilápia-do-nilo. A utilização dos alimentos naturais, in natura ou bioencapsulados, resultou em melhor desempenho para a espécie estudada.

LU et al. (2004) utilizaram microalgas como dieta alimentar durante o período larval da tilápia-do-nilo e constataram que $S$. platensis foi a mais eficiente. Seu caráter filamentoso facilitou a retenção pelos rastros branquiais das tilápias, aumentando sua ingestão e posterior assimilação.

TAKEUCHI et al. (2002) ao alimentarem juvenis de tilápia-do-nilo com $S$. platensis seca e ração comercial observaram melhor índice de crescimento nos peixes que consumiram a microalga. Esses bons resultados com inclusão de $S$. platensis em dietas para tilápia corroboram com os encontrados por LU et al. (2003), que ofertaram a microalga seca para os animais. Durante todo o cultivo, a sobrevivência dos peixes, em ambos os tratamentos, não apresentou diferença significativa $(\mathrm{P}<0,05)$, ficando em $71,66 \pm 4,72 \%$ e $83,33 \pm 3,05 \%$ para o tratamento que recebeu apenas ração e o que recebeu ração e $S$. platensis, respectivamente. HENA et al. (2005) comprovaram que $O$. niloticus apresenta menor mortalidade em água de baixa salinidade.

$\mathrm{Na}$ análise gonadal dos peixes constatou-se que não houve indução sexual em ambos os tratamentos. Verificaram-se índices de $47,5 \%$ de machos para os peixes cultivados sem a microalga e $59,09 \%$ para os peixes cultivados com $S$. platensis. A falta de eficiência do processo pode ser explicada pelo fato de a aclimatação das tilápias ter sido realizada concomitantemente à administração do hormônio masculino, já que foram necessárias constantes trocas de água doce por água

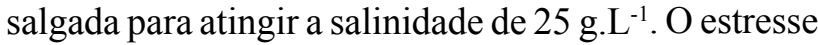
causado pela aclimatação e pela alta salinidade pode ter inibido o processo de masculinização. Segundo PHELPS \& POPMA (2000), os principais fatores que podem afetar a eficiência da masculinização 
em tilápias são: inadequado tamanho das larvas (>14 mm), duração do tratamento hormonal, aspectos ambientais (temperatura, qualidade da água e salinidade elevada) e dose hormonal. Melhores índices de masculinização foram encontrados por SPARKS et al. (2003), ao cultivar Oreochromis mossambicus em água salgada, com alimento à base de ração contendo 17 $\alpha$-metiltestosterona. BOMBARDELLI \& HAYASHI (2005) obtiveram $85,19 \%$ de machos com esse an-

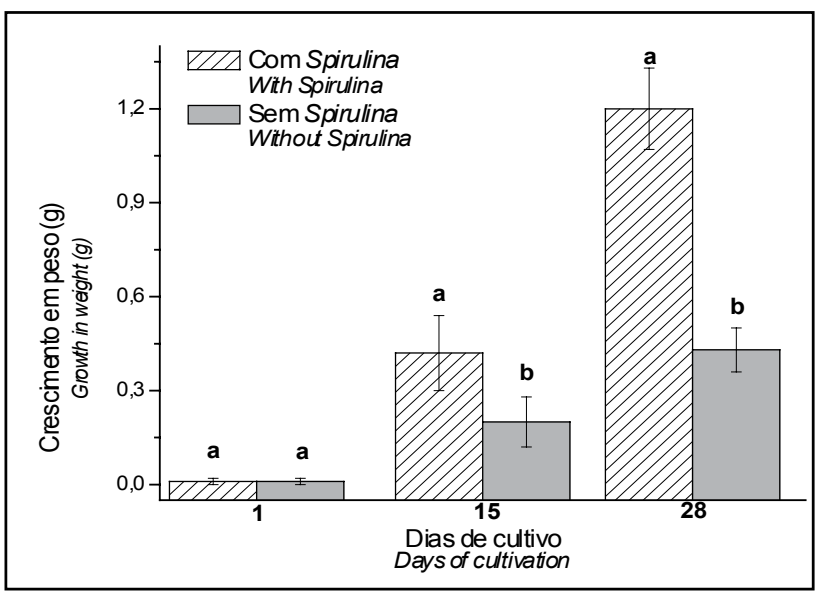

FIGURA 1. Crescimento em peso (g) de tilápias-do-nilo, O. niloticus, durante a fase de reversão sexual em água salobra (25 g.L $\left.\mathrm{L}^{-1}\right)$, na presença e na ausência de $S$. platensis.

Letras distintas sobre as barras de erro indicam diferenças significativas no nível de $5 \%$.

Quando cultivadas em água salina durante o período de reversão sexual, pós-larvas de tilápia-do-nilo apresentam melhor desenvolvimento e taxas de sobrevivência na presença de ração e Spirulina platensis, em relação àquelas alimentadas apenas com ração. No entanto, não foi possível obter índices aceitáveis de masculinização após a administração do hormônio através da ração. Dessa forma, sugere-se realizar em experimentos futuros, a aclimatação dos peixes à salinidade desejada antes do início do tratamento hormonal e/ou trabalhar com salinidades mais amenas.

\section{AGRADECIMENTOS}

drógeno, a partir de banhos de imersão em água doce. Índices de masculinização superiores a 95\% foram conseguidos por YASUI et al. (2007), ao cultivarem a tilápia-do-nilo tailandesa utilizando o hormônio incluso na ração. Raramente há $100 \%$ de sucesso, em virtude da aparente resistência ao hormônio da porcentagem (1-5\%) de fêmeas submetidas ao processo (BOCEK et al., 1992).

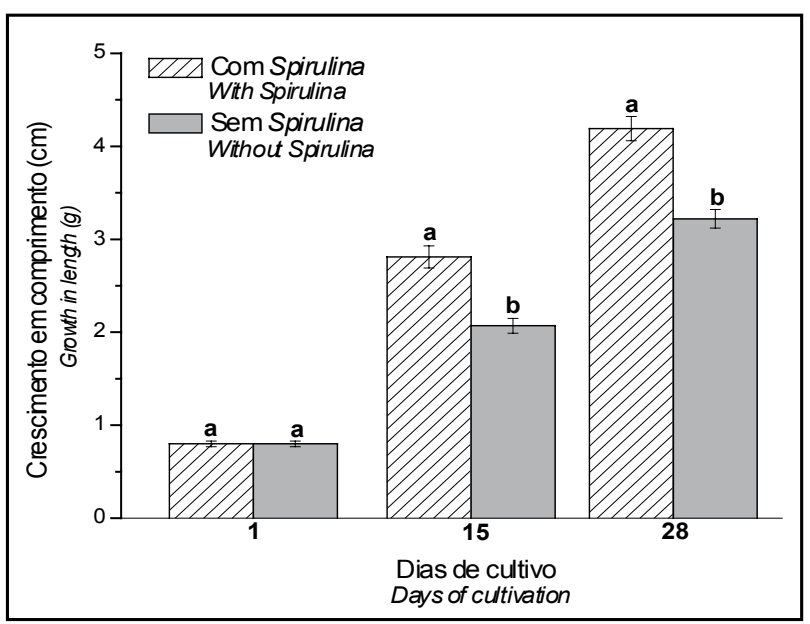

FIGURA 2. Crescimento em comprimento $(\mathrm{cm})$ de tilápias-do-nilo, O. niloticus, durante a fase de reversão sexual em água salobra $(25$ g.L $\left.\mathrm{L}^{-1}\right)$, na presença e na ausência de $S$. platensis. Letras distintas sobre as barras de erro indicam diferenças significativas no nível de $5 \%$.

\section{CONCLUSÃO}

À Coordenação de Aperfeiçoamento de Pessoal de Nível Superior (Capes), ao Conselho Nacional de Pesquisa (CNPq) e à Fundação Cearense de apoio e Desenvolvimento Científico (FUNCAP), pelo auxílio financeiro para a pesquisa.

\section{REFERÊNCIAS}

BELAY, A.; KATO, T.; OTA, Y. Spirulina (Arthrospira): potential application as an animal feed supplement. Journal of Applied Phycology, v. 8, n. 4-5, p. 303-311, 1996.

BEZERRA, K. S.; SANTOS, A. J. G.; LEITE, M. R.; SILVA, A. 
M. da; LIMA, M. R. Crescimento e sobrevivência da tilápia chitralada submetida a diferentes fotoperíodos. Pesquisa Agropecuária Brasileira, v. 43, n. 6, p. 737-743, 2008.

BOCEK, A.; PHELPS, R. P.; POPMA, T. J. Effect of feeding frequency on sex reversal and growth of Nile tilapia, Oreochromis niloticus. Journal of Applied Aquaculture, v. 1, n. 3, p. 97-103, 1992.

BOMBARDELLI, R. A.; HAYASHI, C. Masculinização de larvas de tilápia-do-nilo (Oreochromis niloticus L.) a partir de banhos de imersão com 17a-metiltestosterona. Revista Brasileira de Zootecnia, v. 34, n. 2, p. 365-372, 2005.

CYRINO, J. E. P.; URBINATI, E. C.; FRACALOSSI, D. M.; CASTAGNOLLI, N. Tópicos especiais em piscicultura de água doce tropical intensiva. Sociedade Brasileira de Aquicultura e Biologia Aquática. São Paulo: Editora Tecart, 2004. 345 p.

EL-SAYED, A. M.; KAWANNA, M. Effects of photoperiod on the performance of farmed Nile tilapia Oreochromis niloticus: i growth, feed utilization efficiency and survival of fry and fingerlings. Aquaculture, v. 231, n. 1-4, p. 393-402, 2004.

EL-SAYED, A. M.; MANSOUR, C. R.; EZZAT, A. A. Effects of dietary lipid source on spawning performance of Nile tilapia (Oreochromis niloticus) broodstock reared at different water salinities. Aquaculture, v. 248, n. 1-4, p. 187- 196, 2005.

ERNST, D. H.; WATANABE, W. O.; ELLINGSON, L. J. Commercial scale production of Florida red tilapia seed in low and brackish salinity tanks. Journal World Aquaculture Society, v. 22, n. 1, p. 36-44, 1991.

FAO. The state of world fisheries and aquaculture 2008. Rome: Food and Agriculture Organization of the United Nations (FAO), 2009. 196 p.

FONTAINHAS-FERNANDES, A.; GOMES, E.; REISHENRIQUES, M. A.; COIMBRA, J. Efeito da suplementação da dieta com $\mathrm{NaCl}$ no crescimento de tilápia Oreochromis niloticus cultivada em diferentes salinidades. Arquivo Brasileiro de Medicina Veterinária e Zootecnia, v. 54, n. 2, p. 204-211, 2002.

GUERRERO, R. D.; SHELTON, W. L. An aceto-carmine squash method for sexing juvenile fish. The Progressive Fish-Culturist, v. 36 , n. 1, p. 56-56, 1974.

HAYASHI, C.; BOSCOLO, W. R.; SOARES, C. M.; BOSCOLO, V. R.; GALDIOLI, E. M. Uso de diferentes graus de moagem dos ingredientes em dietas para a tilápia-do-nilo (Oreochromis niloticus L.) na fase de crescimento. Acta Scientiarum, v. 21, n. 3, p. 733-737, 1999.

HENA, A.; KAMAL, M.; MAIR, G. C. Salinity tolerance in superior genotypes of tilapia, Oreochromis niloticus, Oreochromis mossambicus and their hybrids. Aquaculture, v. 247, n. 1-4, p. 189-201, 2005.

HISANO, H.; SAMPAIO, F. G.; BARROS, M. M.; PEZZATO, L. E. Composição nutricional e digestibilidade aparente da levedura íntegra, da levedura autolisada e da parede celular pela tilápia-do-nilo. Ciência Animal Brasileira, v. 9, n. 1, p. 43-49, 2008.

KUBITZA, F. Tilápia: tecnologia e planejamento na produção comercial. Jundiaí: F. Kubitza, 2000. 285 p.

KUBITZA, F. Tilápia em água salobra e salgada. Revista Panorama da Aquicultura, v. 15, n. 88, p. 14-18, 2005.

LU, J.; TAKEUCHI, T.; OGAWA, H. Flesh quality of tilapia Oreochromis niloticus fed solely on raw Spirulina. Fisheries Sciences, v. 69, n. 3, p. 529-534, 2003.

LU, J.; TAKEUCHI, T; SOTOH, H. Ingestion and assimilation of three species of freshwater algae by larval tilapia Oreochromis niloticus. Aquaculture, v. 238, n. 1-4, p. 437-449, 2004.

MAINARDES-PINTO, C. S. R.; FENERICH-VERANI, N.; CAMPOS, B. E. S.; SILVA, A.L. Masculinização da tilápia-do-nilo, Oreochromis niloticus, utilizando diferentes rações e diferentes doses de 17 a-Metiltestosterona. Revista Brasileira de Zootecnia, v. 29, n. 3 , p. $654-659,2000$.

MEURER, F.; HAYASHI, C.; BOSCOLO, W. R. Influência do processamento da ração no desempenho e sobrevivência da tilápia-do-nilo durante a reversão sexual. Revista Brasileira de Zootecnia, v. 32, n. 2, p. 262-267, 2003.

MICROCAL SOFTWARE ORIGIN ${ }^{\circledR}$ 6.0 PROFESSIONAL. Origin data analysis and technical graphics. USA: Microcal Software Inc., 1999.

MIRANDA, M. S.; CINTRA, R. G.; BARROS, S. B. M.; MANCINI, J. Antioxidant activity of the microalga Spirulina maxima. Brazilian Journal of Medical and Biological Research, v. 31, n. 8, p. 1.075-1.079, 1998.

MOREIRA, R. L.; COSTA, J. M. da; QUEIROZ, R. V. de; DE MOURA, P. S. de; FARIAS, W. R. L. Utilização de Spirulina platensis como suplemento alimentar durante a reversão sexual de tilápia-do-nilo. Revista Caatinga, v. 23, n. 2, p. 134-141, 2010.

PIÑERO-ESTRADA, J. E.; BERMEJO-BESCÓS, P.; VILLAR DEL FRESNO, A. M. Antioxidant activity of different fractions of Spirulina platensis protean extract. II Farmaco, v. 56, n. 5-7, p. 497-500, 2001.

PHELPS, R. P.; POPMA, T. J. Sex reversal of tilapia. In: 
COSTAPIERCE, B. A.; RAKOCY, J. E. (Eds.). Tilapia aquaculture in the Americas. Louisiana: The World Aquaculture Society, 2000. v. 2, p. 34-59.

SANTOS, C. H. A.; LOURENÇO, J. A.; IGARASHI, M. A. Crescimento de tilápia-do-nilo alimentada com peixes marinhos provenientes da pesca do camarão. Ciência Animal Brasileira, v. 8, n. 2 , p. $185-192,2007$.

SHELTON, W. L.; RODRIGUES-GUERRERO, D.; LOPESMACIAS, J. Factors affecting androgen sex reversal of tilápia aurea. Aquaculture, v. 25, n. 1, p. 59-65, 1981.

SIPAUBA-TAVARES, L. H.; ROCHA, O. Produção de plâncton (fitoplâncton e zooplâncton) para alimentação de organismos aquáticos. São Carlos: RiMa, 2003. 106 p.

SPARKS, R. T.; SHEPHERD, B. S.; RON, B.; RICHMAN III, H.; RILEYA, L. G.; IWAMAD, G. K.; HIRANO, T.; GRAUA, E. G. Effects of environmental salinity and 17a-methyltestosterone on growth and oxygen consumption in the tilapia, Oreochromis mossambicus. Comparative Biochemistry and Physiology Part B, v. 136, n. 4, p. 657-665, 2003.

TAKEUCHI, T.; LU J.; YOSHIZAKI G.; SATOH. S. Effect on the growth and body composition of juvenile tilapia Oreochromis niloticus fed raw Spirulina. Fisheries Science, v. 68, n. 1, p.
34-40, 2002.

TENDENCIA, E. A.; DELA PEÑA, M. R.; CHORESCA JR, C. $\mathrm{H}$. Efficiency of Chlorella sp. and tilapia Hornorum in controlling the growth of luminous bacteria in a simulated shrimp culture environment. Aquaculture, v. 249, n. 1-4, p. 55-62, 2005.

VINATEA, L. Princípios químicos de qualidade de água em aquicultura. 2. ed. Florianópolis: Editora da UFSC. 883 p. 2004.

VONSHAK, A. Spirulina platensis (Arthrospira) physiology, cell-biology and biotechnology. London: Taylor \& Francis, 1997. $233 \mathrm{p}$.

WASSERMANN, G. J.; AFONSO, L. O. B. Validation of the aceto-carmin technique for evaluating phenotypic sex in Nile tilapia (Oreochromis niloticus) fry. Ciência Rural, v. 32, n. 1, p.113-139, 2002.

YASUI, G. S.; SANTOS, L. C. dos; SHIMODA, E.; RIBEIROFILHO, O. P.; CALADO, L. L.; FREITAS, A. S.; VIDAL, M. V.; FERREIRA, E. B. Masculinização de três linhagens de tilápias-do-nilo utilizando o andrógeno sintético $17 \alpha$-metil-testosterona. Zootecnia Tropical, v. 25, n. 4, p. 307-310, 2007.

Protocolado em: 15 abr. 2010. Aceito em: 19 nov. 2010. 